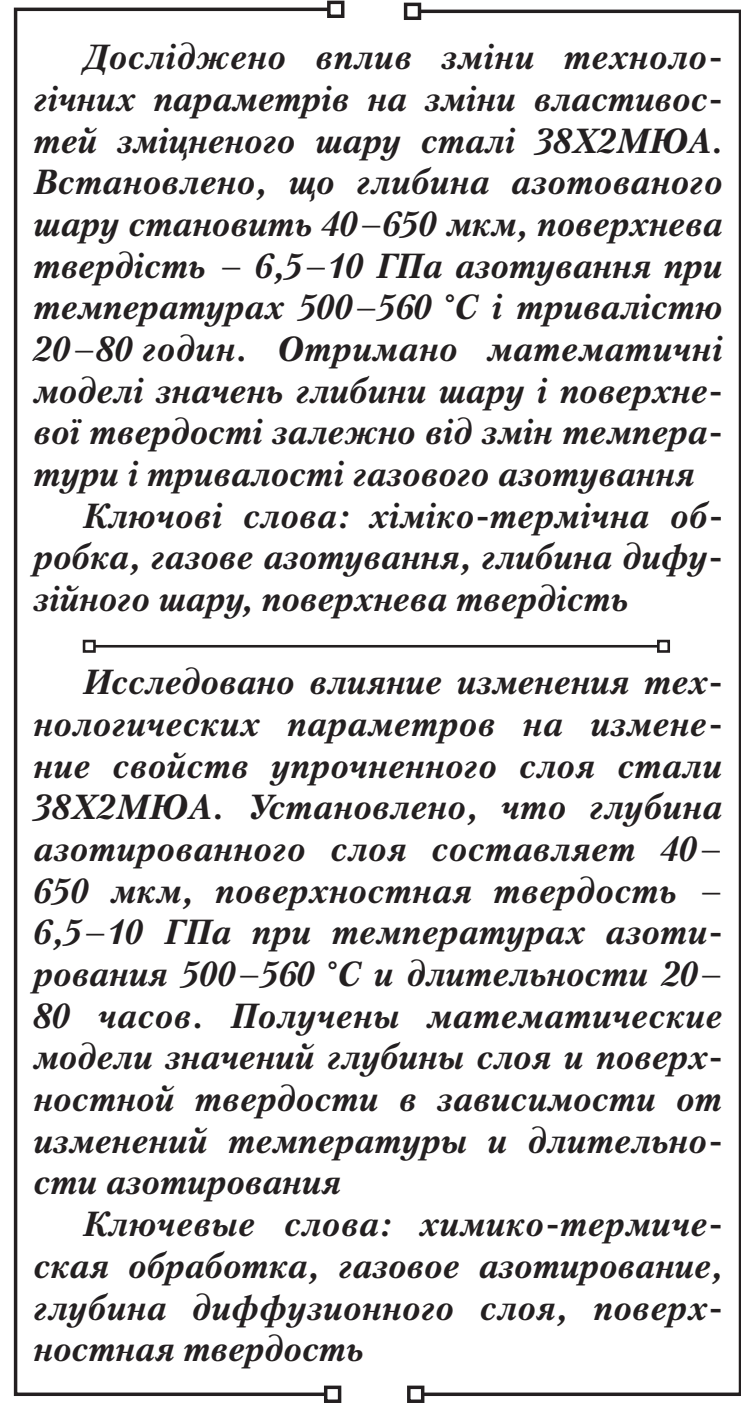

UDC 621.785 .53

DOI: $10.15587 / 1729-4061.2016 .69809$

\section{THE CHOICE OF THE OPTIMAL TEMPERATURE AND TIME PARAMETERS OF GAS NITRIDING OF STEEL}

D h a f e r W a d e e A I - R e k a b y
Department of Materials Science*
V . K o s t y k
PhD, Associate Professor
Department of Materials Science*
E-mail: vikakostik@yandex.ua
K. Ko s t y k
PhD, Associate Professor
Department of Foundry*
E-mail: eklitus@yandex.ru

A. G lotk a

$\mathrm{PhD}$, Associate Professor Department of Physical science**

M. Che che I

Postgraduate student Department of Machines and Technologies of Foundry**

E-mail: nchechel@gmail.com

*National technical University «Kharkiv Polytechnic Institute»

Bagaleia str., 21, Kharkiv, Ukraine, 61002

**Zaporozhye National Technical University Zhukovskogo str., 64, Zaporozhye, Ukraine, 69063

\section{Introduction}

One of the most effective and widespread methods of surface hardening of steels is nitriding. Hardening occurs due to the formation of nitrides, carbonitrides of iron and alloying elements of steel, which significantly increase the surface hardness, wear resistance and seizure resistance, corrosion resistance of parts.

The most common nitriding methods are gas nitriding and plasma nitriding. Despite being very long and laborious process, gas nitriding is widely used today for hardening of parts of a wide range of applications [1].

However, the formation of the diffusion layer and the mechanism of structure formation of the hardened layers is quite a complex process, depending on many factors, and is not fully understood [2]. Mathematical modeling and forecasting is an important problem and plays an essential technological role. Also, the choice of optimum parameters of nitriding remains a complex and controversial issue today.

Mathematical modeling is the most appropriate method to simplify and reduce the cost of the process development, which allows you to quickly obtain the necessary information about the main operational properties of the hardened layer, the structure of the nitride and carbonitride layers under the change of the temperature and time characteristics.

\section{Literature review and problem statement}

There are various methods of surface hardening of steel parts. The most common are the following:

- hardening by creating a film on the product surface (chemical, electroplating, sputtering). The main shortcoming is the low adhesion (cohesion) of the formed coating to the product requiring thorough preparation (cleaning) of the surface of the latter. The probability of hydrogenation of the protected metal should also be noted, especially in case of non-compliance with treatment conditions, leading to hydrogen embrittlement and unattractive surface of the product. A significant drawback of this method is the formation of toxic and environmentally harmful waste, which must be subjected to careful purification [3];

- hardening by diffusion saturation, changing the chemical composition of the metal, resulting in the steel surface having the layers of high-alloy solid solutions of diffusing elements in iron, creating fundamentally different physicochemical properties of the surface, protective layers of the product. The product, whose surface is enriched with these elements, acquires valuable properties, including high heat resistance, corrosion resistance, wear resistance and hardness. Diffusion of chromium, aluminum and other metals is much slower than that of carbon 
and nitrogen, because the latter form interstitial solutions with iron, and metals - substitution solutions. Under the same temperature and time conditions, the diffusion layers are tens or even hundreds of times thinner in the metallization process than in carburizing. This low diffusion rate prevents the widespread application of diffusion saturation processes in the industry, since they are costly and carried out at high temperatures $\left(1000-1200{ }^{\circ} \mathrm{C}\right)$ for a long time. Only special properties of the layer and the possibility to save the alloying elements using diffusion metallization processes resulted in some of their application in the industry [4];

- improvement of the operational properties due to structural changes in the surface layer (electrophysical treatment, thermophysical treatment, machining, surfacing). The main disadvantages of this method are the possibility of structural transformations in the base metal, in particular, the formation of coarse-grained structure; the emergence of new brittle phases; the occurrence of deformations in the processed products; the formation of large tensile stresses in the surface layer of parts, reaching $500 \mathrm{MPa}$; the difficulty of surfacing of small complex-shape parts [5];

- hardening by treatment in the magnetic field environment when changing the energy reserve of the surface layer. This treatment promotes the occurrence of negative factors such as the formation of large crystallites (up to $50 \mathrm{~mm}$ ), wide strip magnetic domains extending from grain to grain and, as a result, the speed of movement of domain walls and magnetic eddy current losses increase (up to $85 \%$ of total) under the magnetization reversal [6];

- change in surface properties by varying the roughness of the surface layer (various types of polishing, plastic deformation, machining). The structure and properties, along with the size and shape, change in the plastically deformed product. This allows the use of plastic deformation as the process operation that changes the structure and properties of metals and alloys in the desired direction. Plastic deformation becomes of particular importance when metals and alloys do not have phase transformations in the solid state and heat treatment can not change their structure and properties (such as austenitic and ferritic alloy steels). Plastic deformation takes place not only under the action of an external force, but also under the influence of internal phase transformations accompanied by volume changes (interfacial hardening). Interfacial hardening influences the structure and significantly affects the formation of properties during heat treatment of metals and alloys [7].

Thus, all of these methods have both advantages and disadvantages. The main disadvantages are the poor abrasion resistance, insufficient coating thickness, high cost, complexity of hardening and other [8].

To date, the choice of the hardening method must be economically sound and tested under specific conditions for each type of the hardened product.

The usefulness of the hardening method is affected by certain factors, depending on the operating conditions of the final product. Evaluation of the reliability of the choice of a particular method is possible only when considering all factors and their relationship. In this regard, a detailed study of the major factors in specific conditions is reasonable.

For parts made of $38 \mathrm{Cr} 2 \mathrm{MoAl}$ steel, nitriding is the most appropriate method of hardening [9]. Despite the wide popularity of gas ni- triding, the issue of optimum process parameters remains unresolved.

\section{Research goal and objectives}

The goal of the research is to select the optimum temperature and time parameters of gas nitriding of $38 \mathrm{Cr} 2 \mathrm{MoAl}$ steel.

To achieve this goal, it is necessary to solve the following tasks:

- to investigate the structure formation of diffusion layers after gas nitriding;

- to obtain a mathematical description of changes in the depth of the diffusion layer and surface hardness, handy for the process engineer of thermochemical treatment;

- to find the optimum temperature and time parameters of gas nitriding of $38 \mathrm{Cr} 2 \mathrm{MoAl}$ steel.

\section{Materials and methods of the gas nitriding experiments and the study of the properties of the diffusion layer of steel}

The paper examines the hardening of the bevel gear (Fig. 1) made of 38Cr2MoAl steel (GOST 4543-71), foreign counterparts of which are A290C1M (USA), 41CrAlMo7 (EU, Germany), SACM64 (Japan), 40CAD6-12 (France), 905M39 (England), 38CrMoAl (China) steels.

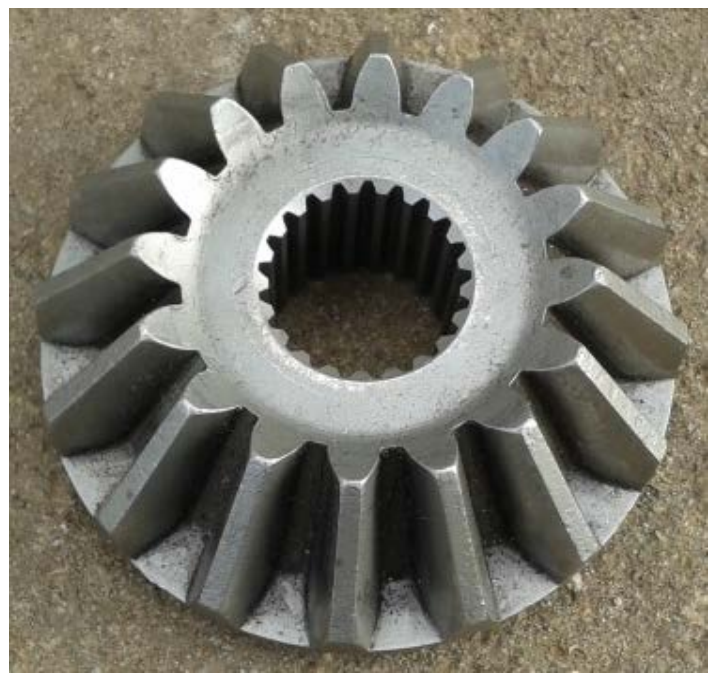

Fig. 1. Bevel gear

The technology of gas nitriding of parts (Fig. 2) was performed in the electric shaft-type furnace SShAM-12.12/7 according to the scheme shown in Fig. 3.

The quenching and tempering consisted in oil quenching of parts at $930-950{ }^{\circ} \mathrm{C}$ and hardening and tempering at $640-680{ }^{\circ} \mathrm{C}$ followed by air cooling.

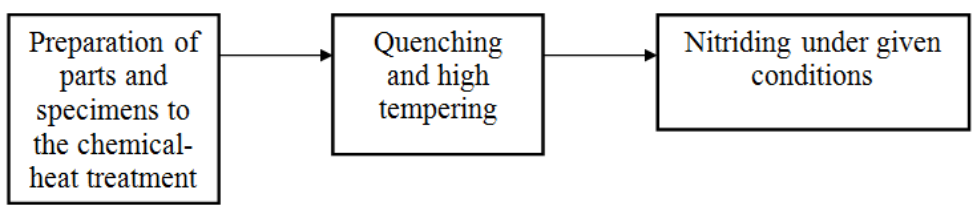

Fig. 2. The technology of the gas nitriding process 


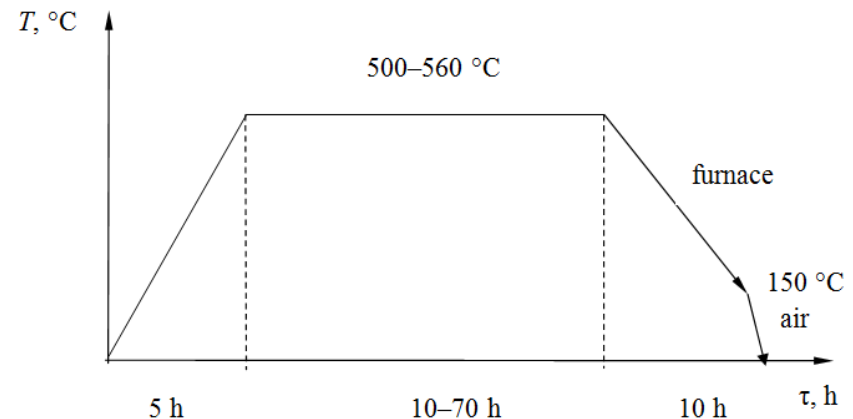

Fig. 3. The scheme of gas nitriding of parts in the shaft furnace

Nitriding of bevel gears and reference specimens was performed in the ammonia atmosphere, according to the technical requirements of the furnace [10].

Preparation of parts and reference specimens to nitriding consisted in washing with gasoline, acetone and drying.

The microstructure of the nitrided case was investigated by optical microscopy using the MIM-7 microscope according to the standard procedure at various magnifications, as well as the 106I-SEM scanning electron microscope.

The distance from the surface to the layer where the hardness was different from that of the core by $50 \mathrm{MPa}$ was taken as the nitrided case depth (Fig. 4).

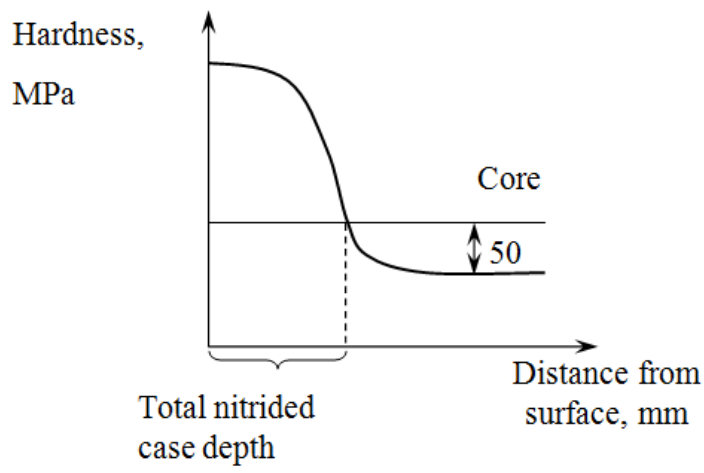

Fig. 4. The scheme for determining the total nitrided case depth

To measure the microhardness, the PMT-3 hardness tester was used at loads of 50,100 grams and 7-15 exposure, according to the standard procedure (GOST 9450-76).

Experiments were carried out at the points of the second-order orthogonal central composite design: gas nitriding of $38 \mathrm{Cr} 2 \mathrm{MoAl}$ steel samples was carried out at temperatures of $500-560{ }^{\circ} \mathrm{C}$ for $20-80$ hours. The average values of the data obtained are shown in Tables 1, 2.

Table 1

The experimental values of the nitrided case depth, $\mu \mathrm{m}$

\begin{tabular}{|c|c|c|c|}
\hline \multirow{2}{*}{$\begin{array}{c}\text { Gas nitriding } \\
\text { time, } \mathrm{h}\end{array}$} & \multicolumn{3}{|c|}{ Nitriding temperature, ${ }^{\circ} \mathrm{C}$} \\
\cline { 2 - 4 } & 500 & 530 & 560 \\
\hline 20 & 40 & 100 & 190 \\
\hline 50 & 400 & 500 & 540 \\
\hline 80 & 570 & 610 & 650 \\
\hline
\end{tabular}

Table 2

The experimental values of the surface hardness of $38 \mathrm{Cr} 2 \mathrm{MoAl}$ steel after ion nitriding, $\mathrm{GPa}$

\begin{tabular}{|c|c|c|c|}
\hline \multirow{2}{*}{$\begin{array}{c}\text { Gas nitriding } \\
\text { time, } \mathrm{h}\end{array}$} & \multicolumn{3}{|c|}{ Nitriding temperature, ${ }^{\circ} \mathrm{C}$} \\
\cline { 2 - 4 } & 500 & 530 & 560 \\
\hline 20 & 7,5 & 8,5 & 6,5 \\
\hline 50 & 10 & 9,5 & 8 \\
\hline 80 & 9 & 9,2 & 7,5 \\
\hline
\end{tabular}

The gas nitriding temperature $\left(\mathrm{x}_{1}\right)$ and time $\left(\mathrm{x}_{2}\right)$ were taken as input variables, the diffusion layer depth $\left(\mathrm{y}_{1}\right)$, and the surface layer hardness $\left(\mathrm{y}_{2}\right)$ of $38 \mathrm{Cr} 2 \mathrm{MoAl}$ steel - as output variables. The paper presents the average values of $\mathrm{y}_{1}$ and $y_{2}$, obtained as a result of 10 parallel experiments at the points beyond the design.

\section{The results of experiments to determine the nitrided case depth and the surface hardness after gas nitriding}

The microstructure of the alloy steel after the gas nitriding is shown in Fig. 5, electron microscopy - in Fig. 6, respectively. The nitrided case (light region in Fig. 5 and zones 1 and 2 in Fig. 6) and the internal nitriding zone (below the light region in Fig. 5 and zone 3 in Fig. 6) are clearly seen on the microstructures.

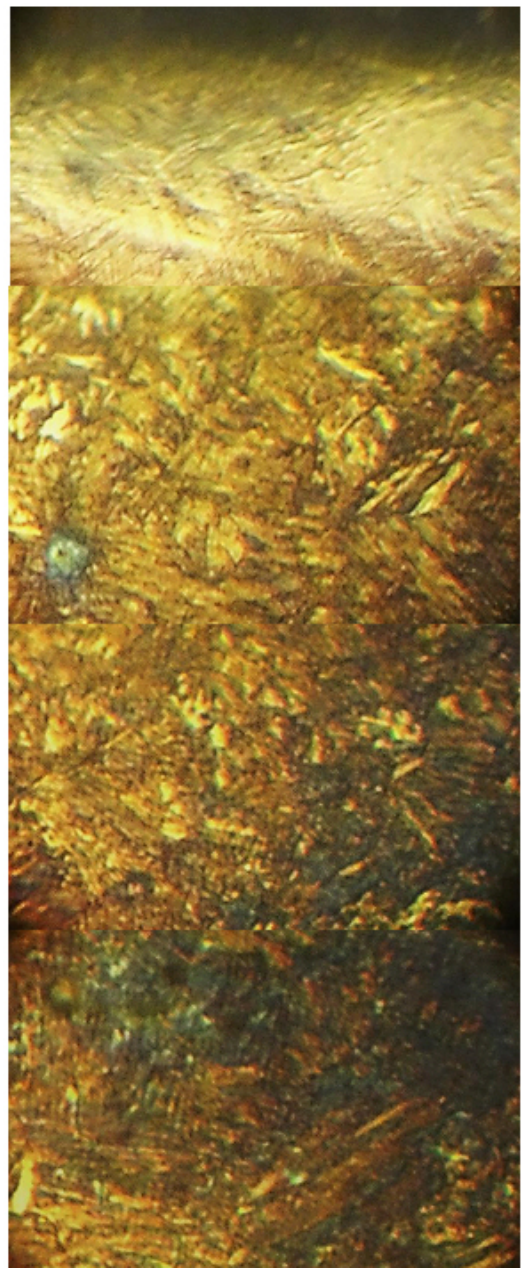

Fig. 5. The microstructure of $38 \mathrm{Cr} 2 \mathrm{MoAl}$ steel after nitriding, $\times 1000$ 


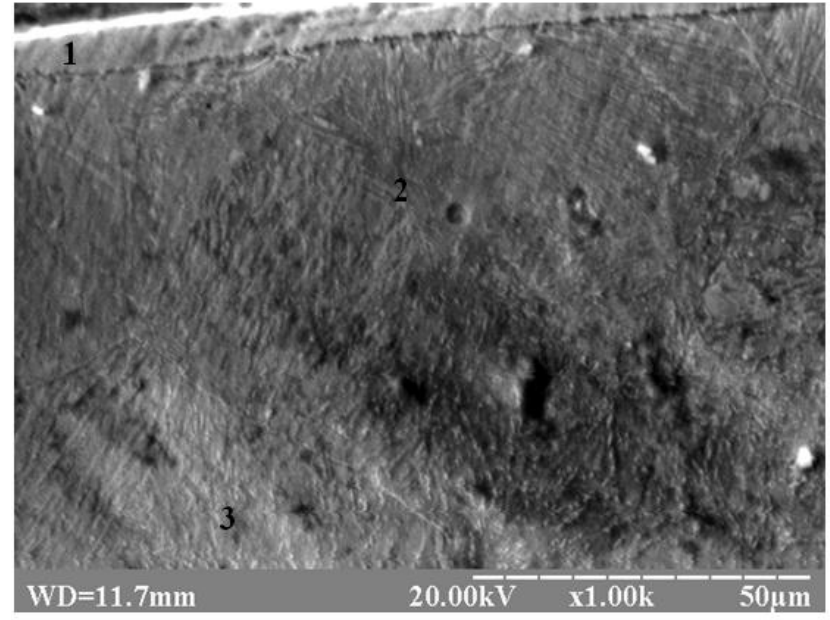

Fig. 6. Electron microscopy of the nitrided case of $38 \mathrm{Cr} 2 \mathrm{MoAl}$ steel

The element composition of the alloying elements and matrix of the steel was determined by the energy-dispersive registration of intensity of the lines of characteristic $\mathrm{X}$-ray radiation of the sample resulting from irradiation of micro-volume of the sample by the electron probe (Fig. 7). Similar spectrograms were obtained for points 2 and 3 shown in Fig. 6. Analysis of the element composition is represented as bar graphs in Fig. 8, 9.

Fig. 8. Distribution of the alloying elements of $38 \mathrm{Cr} 2 \mathrm{MoAl}$ steel in the zones of the diffusion layer after gas nitriding (points $1-3$ - the zones of the nitrided case shown in Fig. 6).

Processing of the data about the depth of the diffusion layer and the surface hardness is represented as bar graphs (Fig. 10, 11). The depth distribution of the microhardness in the diffusion layer is shown in Fig. 12-14.

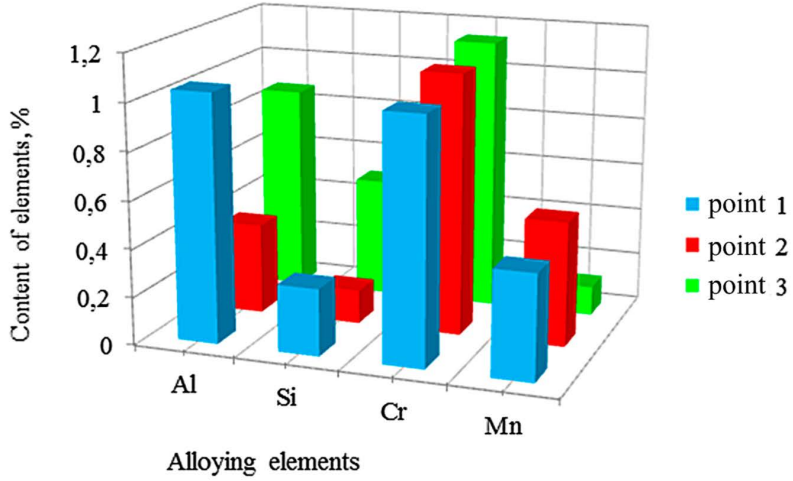

Fig. 8. Distribution of the alloying elements of $38 \mathrm{Cr} 2 \mathrm{MoAl}$ steel in the zones of the diffusion layer after gas nitriding (points 1-3-the zones of the nitrided case shown in Fig. 6)

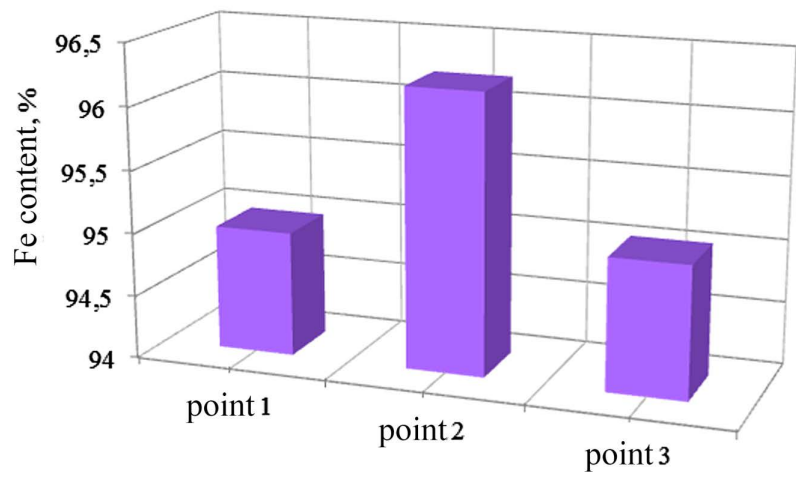

Fig. 9. Distribution of the matrix of $38 \mathrm{Cr} 2 \mathrm{MoAl}$ steel in the zones of the diffusion layer after gas nitriding (points 1-3 - the zones of the nitrided case shown in Fig. 6)

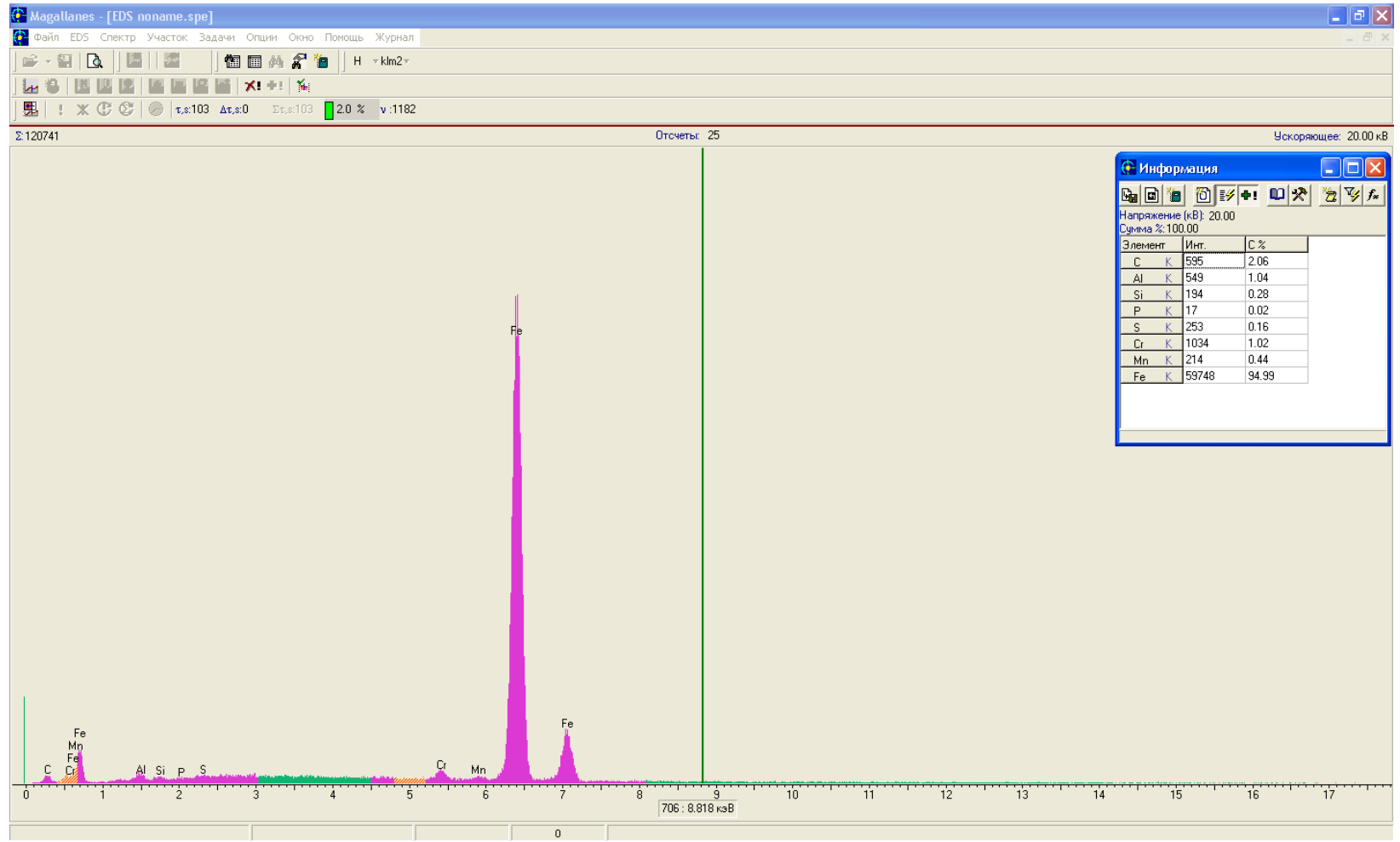

Fig. 7. The intensity of the characteristic $X$-ray radiation lines at the point 1 


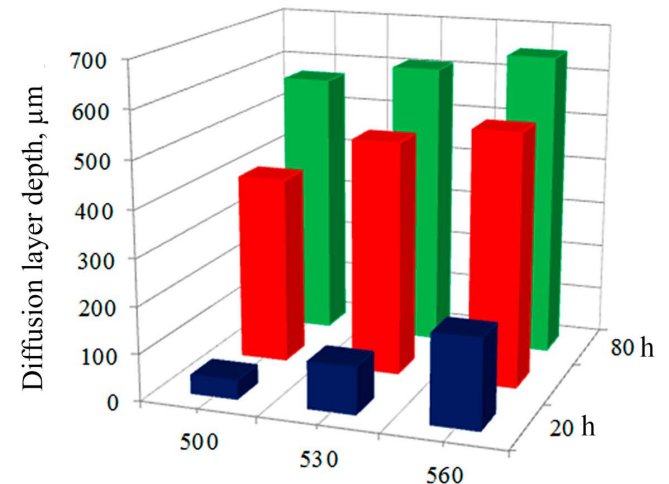

Nitriding temperature ${ }^{\circ} \mathrm{C}$

Fig. 10. The bar graph of the depth distribution of the nitrided case of $38 \mathrm{Cr} 2 \mathrm{MoAl}$ steel after gas nitriding depending on the treatment temperature and time

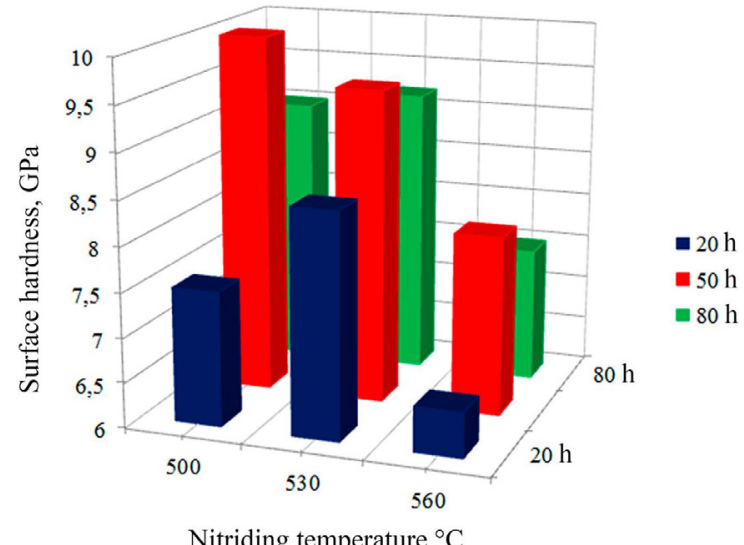

Fig. 11. The bar graph of distribution of the surface hardness of $38 \mathrm{Cr} 2 \mathrm{MoAl}$ steel on changes in gas nitriding temperature and time

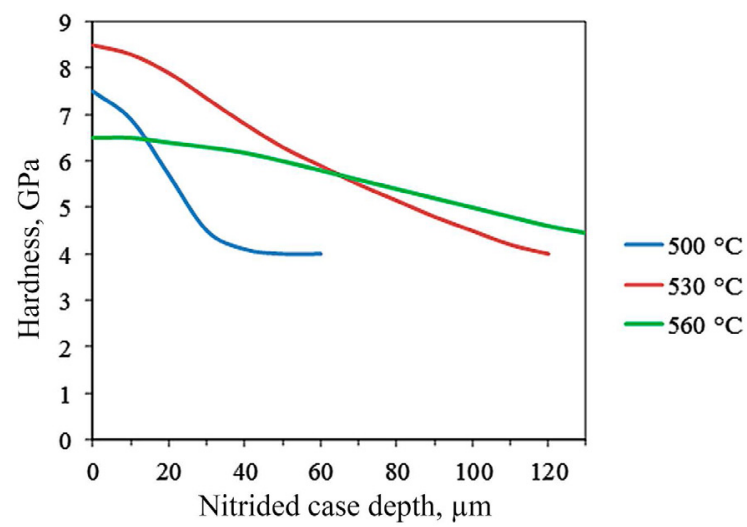

Fig. 12. The distribution of hardness in the diffusion layer of $38 \mathrm{Cr} 2 \mathrm{MoAl}$ steel after 20 -hour gas nitriding

Mathematical models describing the dependences of the nitrided case depth and surface hardness on the temperature and time of thermochemical treatment of steel during gas nitriding can be represented as the quadratic polynomial [9]. The procedure of estimating the coefficients of the model, verification and statistical analysis of the accuracy is given in the study [9]. The resulting model of the case depth, depending on the normalized values of temperature and time of thermochemical treatment is as follows:

$$
\begin{aligned}
& y=402,22222+61,679 \cdot x_{1}+246,716 \cdot x_{2}- \\
& -11,727 \cdot x_{1}^{2}-116,727 \cdot x_{2}^{2}-17,5 \cdot x_{1} \cdot x_{2} .
\end{aligned}
$$

The graphic representation of the values of the obtained dependence (1) is shown in Fig. 15.

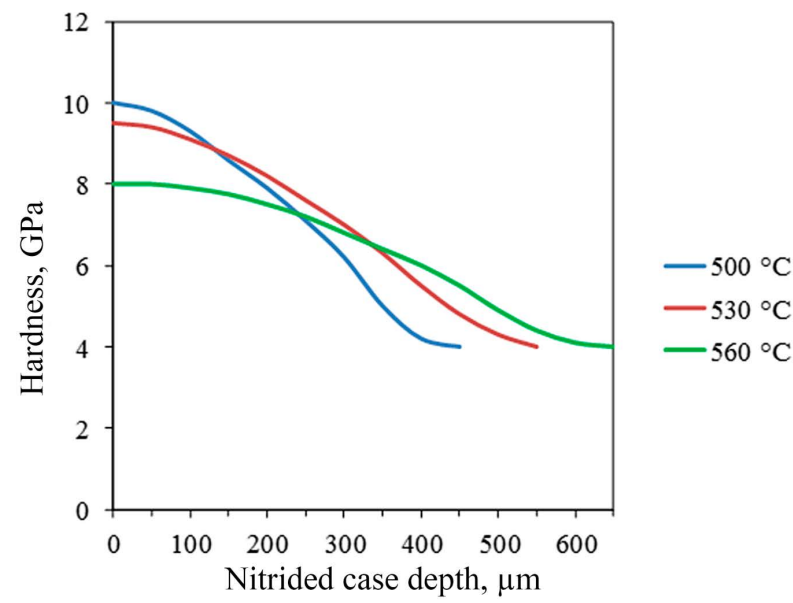

Fig. 13. The distribution of hardness in the diffusion layer of $38 \mathrm{Cr} 2 \mathrm{MoAl}$ steel after 50 -hour gas nitriding

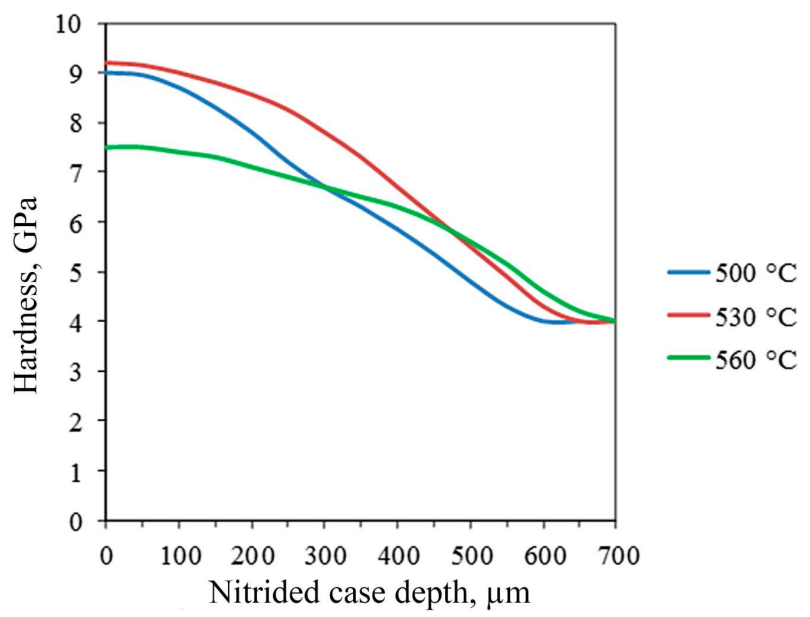

Fig. 14. The distribution of hardness in the diffusion layer of $38 \mathrm{Cr} 2 \mathrm{MoAl}$ steel after 80 -hour gas nitriding

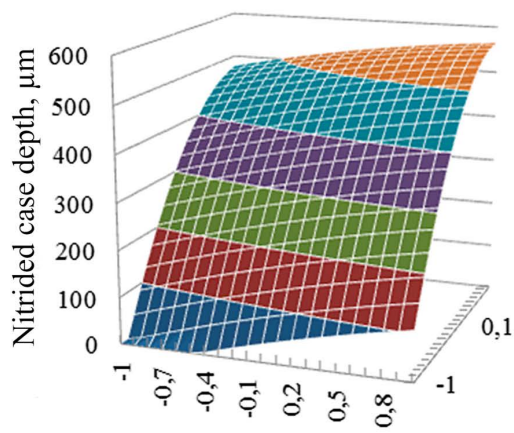

$=500-600$
$=400-500$
$=300-400$
$=200-300$
$=100-200$
$=0-100$
Nitriding time in
normalized form

Nitriding temperature in normalized form

Fig. 15. The graphic representation of the model (1)

The mathematical model describing the effect of the nitriding temperature and time on the values of the nitrided case surface hardness is generally represented as follows: 


$$
\begin{aligned}
& y=8,41-0,75015 \cdot x_{1}+0,5334 \cdot x_{2}- \\
& -0,98459 \cdot x_{1}^{2}-1,13459 \cdot x_{2}^{2}-0,125 \cdot x_{1} \cdot x_{2} .
\end{aligned}
$$

The significance test of the coefficients showed that the coefficient $\mathrm{a}_{5}$ may be deemed insignificant, so the model is transformed to the following:

$$
\begin{aligned}
& y=8,41-0,75015 \cdot x_{1}+0,5334 \cdot x_{2}- \\
& -0,98459 \cdot x_{1}^{2}-1,13459 \cdot x_{2}^{2} .
\end{aligned}
$$

The graphic representation of the model (3) is shown in Fig. 16.

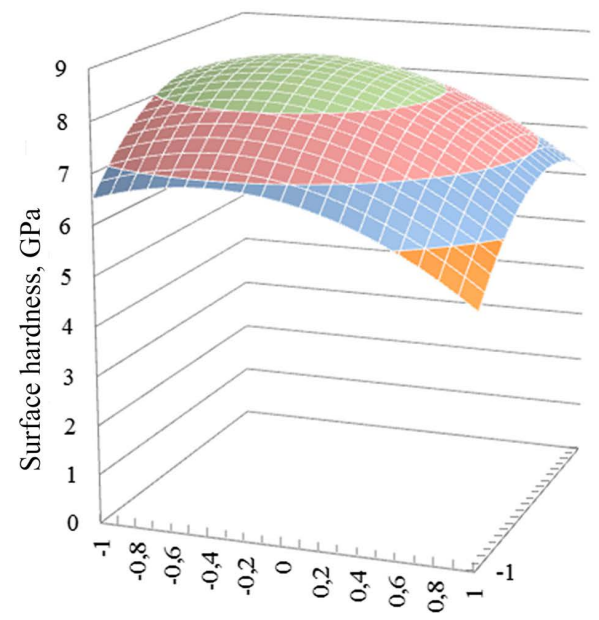

$$
\begin{aligned}
& =8-9 \\
& =7-8 \\
& =6-7 \\
& =5-6
\end{aligned}
$$

Nitriding time in normalized form

Nitriding temperature in normalized form

Fig. 16. The graphic representation of the model (3)

It was experimentally proved that the overrun of the maximum values of the design area (treatment temperature of $560{ }^{\circ} \mathrm{C}$ and time of $80 \mathrm{~h}$ ) leads to the formation of nitride meshes along the grain boundaries in the diffusion layer, which is unacceptable. The overrun of the minimum values (treatment temperature of $500{ }^{\circ} \mathrm{C}$ and time of $20 \mathrm{~h}$ ) leads to the formation of the insufficient and inhomogeneous case, as well as to the appearance of the regions with the absence of the nitrided cases. The analysis of the obtained mathematical relationships (1) and (3) showed that the estimated local maximum of the values is within the experimental design and corresponds to $518.0{ }^{\circ} \mathrm{C}$ and $57.7 \mathrm{~h}$. The local maximum of the diffusion layer depth extends beyond the design, it is a predicted value and corresponds to $588.5{ }^{\circ} \mathrm{C}$ and $77.3 \mathrm{~h}$. Indeed, the increase in temperature promotes the growth of the diffusion layer, however, the temperature parameter should be limited because of the negative structure formation, namely the presence of nitride mesh in the nitrided case, which is unacceptable.

\section{Discussion of the results of simulation of temperature and time parameters of gas nitriding}

As follows from the results, the optimum values of the nitrided case depth and surface hardness are not the same, the most operationally advantageous ratio of them should be found. With increasing temperature and time, the nitrided case depth tends to the maximum values, but the local optimum is reached beyond the boundaries of experimental design. For the surface hardness, the area of the maximum values corresponds to $518.0{ }^{\circ} \mathrm{C}$ and $57.7 \mathrm{~h}$.

Justification of the resulting regularity is associated with the features of structure formation of the diffusion layer during gas nitriding. The increase in the temperature and time parameters promotes the nitrided case growth and provides higher surface hardness. This is due to the formation of increasing amounts of nitrides and carbonitrides. However, a further increase in the treatment time and temperature results in a more intense diffusion of nitrogen into the metal, which is reflected in reduced surface hardness.

The mathematical description of the relationship of input and output variables provides more convenient working conditions to the process engineer of thermochemical treatment. Based on the given parameters of the nitrided case of the part, the corresponding values of the temperature and time of thermochemical treatment can be found. Also, this kind of description provides the ability to solve the inverse problem, namely, to estimate the supposed depth of the nitrided case and surface hardness under the influence of temperature and time of gas nitriding.

This type of description allows determining specific conditions of gas nitriding (temperature and time), based on the desired depth of the nitrided case or the surface hardness of $38 \mathrm{Cr} 2 \mathrm{MoAl}$ steel respectively.

\section{Conclusions}

1. Optical and electron microscopy showed that the diffusion layer after gas nitriding in the ammonia environment is the nitrided case and the region of internal nitriding.

2. The mathematical description (1) and (3) is a handy tool in the work of the process engineer of thermochemical treatment. This kind allows determining specific conditions of gas nitriding (temperature and time), based on the desired depth of the nitrided case or the surface hardness of $38 \mathrm{Cr} 2 \mathrm{MoAl}$ steel respectively.

3. The theoretical optimum conditions of gas nitriding are $518.0^{\circ} \mathrm{C}$ and $57.7 \mathrm{~h}$ for the maximum surface hardness and $588.5^{\circ} \mathrm{C}$ and $77.3 \mathrm{~h}$ - for the maximum diffusion layer depth. The value of the nitrided case depth in the area of the maximum values of surface hardness at the nitriding temperature of $518.0{ }^{\circ} \mathrm{C}$ and time of $57.7 \mathrm{~h}$ is $\sim 430 \mu \mathrm{m}$.

\section{References}

1. Gerasimov, S. A. Novyie idei o mehanizme obrazovaniya strukturyi azotirovannyih staley [Text] / S. A. Gerasimov // Metallovedenie i termicheskaya obrabotka metallov. - 2004. - Vol. 1. - P. 13-18.

2. Krukovich, M. G. Modelirovanie protsessa azotirovaniya [Text] / M. G. Krukovich // Metallovedenie i termicheskaya obrabotka metallov. - 2004. - Vol. 1. - P. 24-31

3. Gu, W. Deposition of duplex $\mathrm{Al}_{2} \mathrm{O}_{3}$ /Aluminum coatings on steel using a combined technique of arc spraying and plasma electrolytic oxidation [Text] / W. Gu, D. Shen, Y. Wang, G. Chen, W. Feng, G. Zhang et. al. //Applied surface science. - 2006. - Vol. 252, Issue 8. - P. 2927-2932. doi: 10.1016/j.apsusc.2005.04.036 
4. Ai, J. H. Hydrogen diffusion and trapping in a precipitation-hardened nickel-copper-aluminum alloy Monel K-500 (UNS N05500) [Text] / J. H. Ai, H. M. Ha, R. P. Gangloff, J. R. Scully //Acta Materialia. - 2013. - Vol. 61, Issue 9. - P. 3186-3199. doi: 10.1016/ j.actamat.2013.02.007

5. Penumadu, D. Material science and engineering with neutron imaging [Text] / D. Penumadu. - Neutron Scattering Applications and Techniques, 2009. - P. 209-227. doi: 10.1007/978-0-387-78693-3_12

6. Patwari, M. A. U. Investigation of machinability responses during magnetic field assisted turning process of preheated mild steel [Text] / M. A. U. Patwari, M. N. Mahmood, S. Noor, M. Z. H. Shovon //Procedia Engineering. - 2013. - Vol. 56. - P. 713-718. doi: 10.1016/j.proeng.2013.03.183

7. Saha, R. Fully recrystallized nanostructure fabricated without severe plastic deformation in high-Mn austenitic steel [Text] / R. Saha, R. Ueji, N. Tsuji // Scripta Materialia. - 2013. - Vol. 68, Issue 10. - P. 813-816. doi: 10.1016/j.scriptamat.2013.01.038

8. Thanh, D. T. M. Controlling the electrodeposition, morphology and structure of hydroxyapatite coating on 316L stainless steel [Text] / D. T. M. Thanh, P. T. Nam, N. T. Phuong, L. X. Que, N. Van Anh, T. Hoang, T. Dai Lam // Materials Science and Engineering: C. - 2013. - Vol. 33, Issue 4. - P. 2037-2045. doi: 10.1016/j.msec.2013.01.018

9. Mohanad, M. K. Modeling of the case depth and surface hardness of steel during ion nitriding [Text] / M. K. Mohanad, V. Kostyk, D. Domin, K. Kostyk // Eastern-European Journal of Enterprise Technologies. - 2016. - Vol. 2, Issue 5 (80). - P. 45-49. doi: 10.15587/1729-4061.2016.65454

10. Kostyk, K. O. Research of influence of gas nitriding duration on formation of diffusion layer of steel 20Kh2N4A [Text] / K. O. Kostyk // Odes'kyi Politechnichnyi Universytet. Pratsi. - 2015. - Vol. 2. - P. 14-18. doi: 10.15276/opu.2.46.2015.04

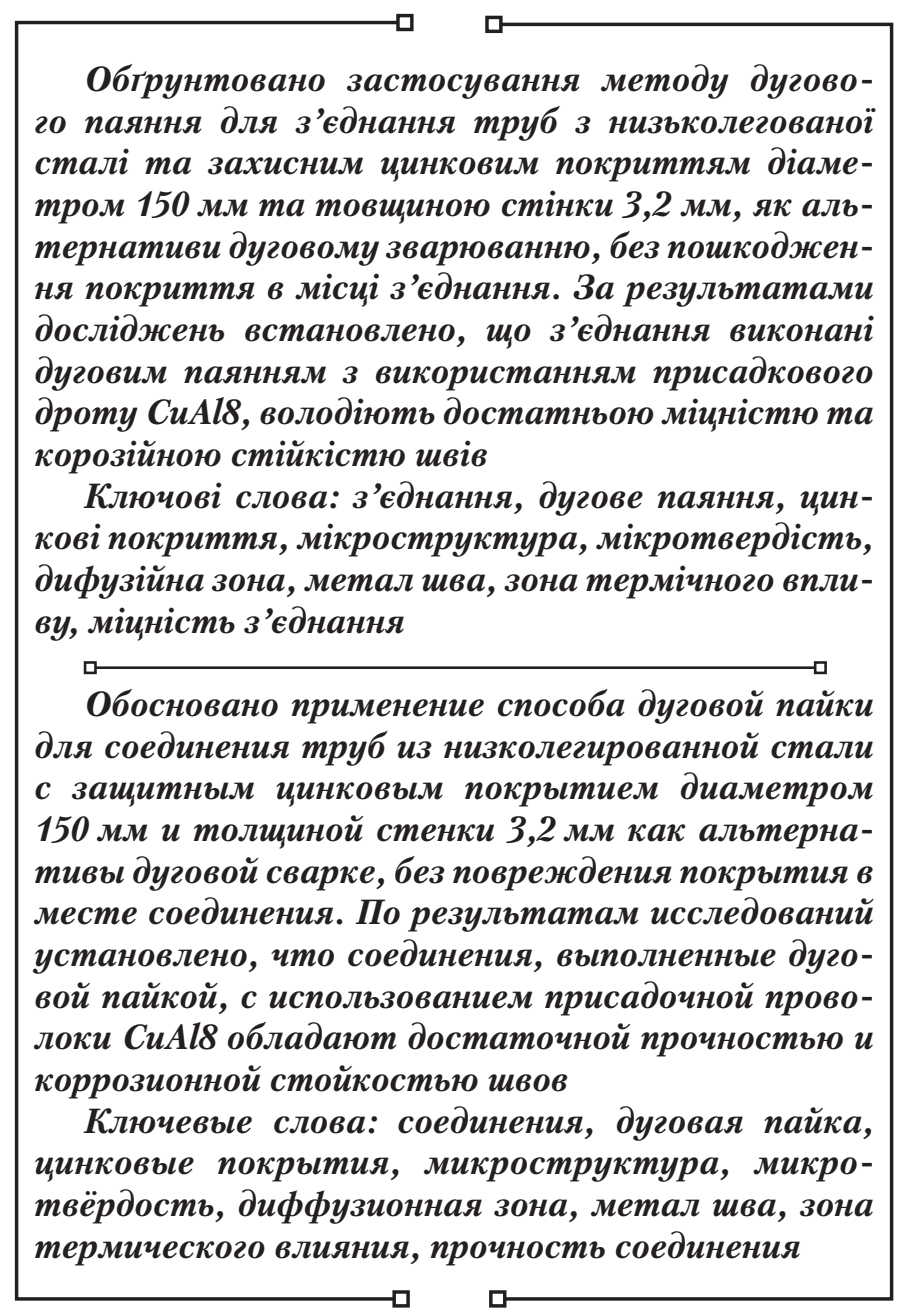

\section{Introduction}

The pipes with protective coating are widely used to lay pipelines for water, steam, oil products transportation. As usual, the pipes which inner diameters are below $150 \mathrm{~mm}$ are used.
UDC 621.791 .317 .5

DOI: $10.15587 / 1729-4061.2016 .70346$

DEVELOPMENT OF THE ZINC COATING PIPE CONNECTION TECHNOLOGY WITH ARC SOLDERING METHOD USING

O. Matviienkiv

Assistant*

E-mail: olegmatvienkiv@gmail.com

P. P r y s y a z h n y u k

$\mathrm{PhD}$, Associate Professor* E-mail: pavlo1752010@yandex.ua

V. M y n d i u k

$\mathrm{PhD}$, Associate Professor**

E-mail: tinlaven@gmail.com *Departments welding constructions and restoration of machine parts $* * *$

**Department of energy management and technical diagnostics $* \star *$ ***Ivano-Frankivsk National Technical University of Oil and Gas Karpatska str., 15, Ivano-Frankivsk, Ukraine, 76019

Applying a thin layer of metal protective coating is the most reliable way of pipes corrosion protection and operation period increasing. Among well-known metal coating, zinc is the most widespread for steel pipes protection. Its electro-negative potential is higher than iron potential. Besides, zinc dissolves slower due to electrochemical reactions. Also, 